\title{
Clinical aspects of systemic sclerosis (scleroderma)
}

\author{
Richard M Silver
}

Systemic sclerosis (scleroderma) is a disease of unknown cause, the hallmark of which is induration of the skin. Although long regarded as a bland fibrotic process, there is now ample evidence of an active inflammatory process underlying the pathogenesis of systemic sclerosis. In addition, microvascular disease and immunological abnormalities are present in most cases. It remains to be determined just how the immunological and microvascular changes relate to the overproduction of collagen and other matrix elements by the fibroblast, but recent data suggest that products of the immune response may directly affect fibroblasts and endothelial cells in vitro.

This review will focus on recent advances in the understanding of several clinical aspects of systemic sclerosis. The reader is referred to several recent chapters and textbooks for a more extensive review. ${ }^{1-3}$

\section{Classification}

Scleroderma may exist as a localised or a systemic disease process. The latter has been delineated 'progressive systemic sclerosis' in the past, but use of this term has been decried as the disease is not always progressive and because of the emotional burden that this term may place on the patient and the patient's family. ${ }^{4}$

In its localised form scleroderma is confined to the skin and adjacent tissues, and it can be classified as linear scleroderma or morphoea (see below). In its systemic form scleroderma may affect a number of visceral organs. Here the classification is somewhat controversial and is based on the extent of cutaneous involvement. Table 1 shows a widely accepted classification, where diffuse (particularly truncal) skin disease is distinguished from limited skin involvement; the latter encompasses and replaces the CREST (calcinosis, Raynaud's phenomenon, oesophageal dysmotility, sclerodactyly, and telangiectasia) variant of scleroderma. Limited cutaneous systemic sclerosis also includes what has been variously designated acrosclerosis, types I and II scleroderma of Barnett, types I and II of the German classification, intermediate cutaneous systemic sclerosis of Giordano, and systemic sclerosis without scleroderma. ${ }^{4}$

A recent editorial summarises data which Division of Immunology and Rheumatology, Medical University of South Carolina, Charleston, South Carolina 294252229 , USA

R M Silver simpler classification shown in table $1 .{ }^{4} \mathrm{By}$ classifying patients into subsets early in the course of the illness, one hopes to identify patients at greater or lesser risk of developing certain visceral complications, as well as provide a more homogeneous group of patients for studies of the pathogenesis, clinical manifestations, and treatment.

\section{Clinical features}

RAYNAUD'S PHENOMENON

Raynaud's phenomenon refers to episodic digital ischaemia provoked by cold or emotion. Although classically described as triphasicthat is, pallor followed by cyanosis, and then hyperaemia accompanied by numbness and pain, such a three colour response does not occur universally. Pallor seems to be the most reliable sign and hyperaemia the least reliable sign in subjects who lack the classic triphasic response. A recently described questionnaire and colour chart may facilitate the diagnosis of Raynaud's phenomenon. ${ }^{6}$

Establishment of the presence or absence of Raynaud's phenomenon is important when evaluating a patient with scleroderma-like skin. The absence of Raynaud's phenomenon should raise the possibility that one might be dealing with a disease other than systemic sclerosis (table 2) as $95 \%$ of patients with systemic sclerosis have Raynaud's phenomenon. This distinction is illustrated by the recently described eosinophilia-myalgia syndrome associated with L-tryptophan ingestion, in which sclerodermalike skin lesions commonly accompanied

Table 1 Subsets of systemic sclerosis. Reproduced, with permission, from ref 4

Diffuse cutaneous systemic sclerosis*

Onset of Raynaud's phenomenon within one year of onset of skin changes (puffy or hidebound)

Truncal and acral skin involvement

Truncal and acral skin involvemente of tendon friction rubs

Presence of tendon friction rubs

oliguric renal failure, diffuse gastrointestinal disease, and oliguric renal failure
myocardial disease

myocardial disease
Absence of anticentromere antibodies

Nailfold capillary dilatation and capillary destruction Antitopoisomerase antibodies ( $30 \%$ of patients)

Limited cutaneous systemic sclerosis

Raynaud's phenomenon for years (occasionally decades) Skin involvement limited to hands, face, feet, and forearms (acral) or absent

A significant late incidence of pulmonary hypertension, with or without interstitial lung disease, trigeminal neuralgia, skin calcifications, telangiectasia

A high incidence of anticentromere antibody $(70-80 \%)$ Dilated nailfold capillary loops; usually without capillary dropout

*Experienced observers note some patients with diffuse cutaneous systemic sclerosis who do not develop organ insufficiency and suggest the term chronic diffuse cutaneous systemic sclerosis for these patients.

sclerosis for these patients. †Nailfold capillary dilatation and destruction may also be seen in patients with dermatomyositis, overlap syndromes, and un differentiated connective tissue disease. These syndromes may be considered as part of the spectrum of scleroderma associate disorders. 
Table 2 Diseases with cutaneous features resembling scleroderma

Eosinophilic fasciitis

Tryptophan associated eosinophilia-myalgia syndrome

Chemical induced disorders

Bleomycin fibrosis

Vinyl chloride disease

Trichloroethylene fibrosis

Toxic oil syndrome

Toxic oil syndrome
Graft versus host disease

Graft versus host disease
Digital sclerosis of diabetes mellitus

Infilal sclerating carcinomas

Infiltrating carci

Scleromyxoedema (papular mucinosis)

Werner's syndrome

Progeria

Rothmund's syndrome

Acrodermatitis chronica atrophicans

Lichen sclerosis et atrophicus

Carcinoid syndrome

Phenylketonuria

Porphyria cutanea tarda

Congenital porphyria

Primary amyloidosis

Acromegaly

myalgia, eosinophilia, and fasciitis (see below). ${ }^{7}$ Few of such cases were accompanied by Raynaud's phenomenon, nor had other diseases which may mimic systemic sclerosis.

The duration of Raynaud's phenomenon before skin involvement is important. Patients with diffuse cutaneous systemic sclerosis and a tendency to early visceral organ damage usually have a brief duration of Raynaud's phenomenon before development of skin changes, whereas patients with limited cutaneous systemic sclerosis usually have many years (often decades) of Raynaud's phenomenon before overt skin and visceral involvement.

An important issue for the clinician is the evaluation of the subject with Raynaud's phenomenon for the presence of an underlying connective tissue disease. Raynaud's phenomenon itself is quite common in the general population, yet only a fraction of such subjects will develop a connective tissue disease. ${ }^{8}$ One survey found the prevalence of Raynaud's phenomenon to be $4.6 \%$ among adults living in South Carolina. ${ }^{9}$ The prevalence may be higher in colder climates.

As Raynaud's phenomenon may herald the development of serious disease, especially connective tissue disease, studies have been undertaken to determine which ancillary tests may be predictive of the evolution to an overt connective tissue disease. Two markers seem to have predictive value for the subsequent development of connective tissue disease (usually systemic sclerosis): (a) abnormal nailfold capillaries and $(b)$ antinuclear antibodies.

Definitely abnormal capillary patterns, detected by nailfold capillary microscopy, indicate an increased risk for the presence or eventual transition to a connective tissue disease. ${ }^{10} \mathrm{~A}$ recent prospective study of patients with Raynaud's phenomenon confirmed this finding and concluded that the presence of abnormal capillaries was the most significant predictor of the subsequent development of systemic sclerosis (odds ratio, 26.82, $\mathrm{p}=0.001) .{ }^{11}$ In addition, the degree of capillary loss assessed by nailfold capillary microscopy may be correlated with clinical and serological features and may assist in the subclassification of systemic sclerosis as diffuse cutaneous or limited cutaneous systemic sclerosis (see table 1). 12

The other marker which may be useful in predicting the presence or eventual development of connective tissue disease in a subject with Raynaud's phenomenon is the antinuclear antibody. Here the predictive value depends on the method and substrate used. Two recent studies showed that the immunoblot technique was more sensitive than indirect immunofluorescence and, furthermore, antibody specificity of antinuclear antibodies as determined by immunoblots was predictive of the development of specific subtypes of systemic sclerosis. ${ }^{13} 14$ In a prospective study of patients with Raynaud's phenomenon and undifferentiated connective tissue disease Kallenberg et al found that the presence of antinuclear antibodies detected by immunoblots at the time of entry into the study was associated with the evolution of symptoms of a connective tissue disease, usually systemic sclerosis. ${ }^{13}$ Furthermore, anticentromere antibody was associated with limited cutaneous systemic sclerosis (sensitivity $60 \%$, specificity 98\%) and anti-Scl-70 antibody was associated with diffuse cutaneous systemic sclerosis (sensitivity $38 \%$, specificity $100 \%$ ). Based on the aforementioned studies, it is recommended that all patients with Raynaud's phenomenon have a complete clinical evaluation, including nailfold capillary microscopy and antinuclear antibody studies which, preferably, test for specific antigens associated with subtypes of systemic sclerosis.

\section{SKIN DISEASE}

Sclerosis of the skin is the hallmark of systemic sclerosis, though rare patients may have typical visceral organ involvement in the absence of skin disease (systemic sclerosis without scleroderma). ${ }^{15}$ Skin thickening is the definitive diagnostic criterion of systemic sclerosis in the vast majority of cases, and the distribution of affected skin serves as the means of classifying patients into one or another subset of systemic sclerosis (see above). Such classification may have important implications for the risk of developing visceral organ involvement and for mortality (table 3$)^{4}$

Three phases of dermal involvement have been described. Firstly, there is an oedematous phase, often presenting as stiff and puffy fingers and hands. In this initial phase the condition is often difficult to distinguish from other connective tissue diseases or carpal tunnel syndrome; nailfold capillary microscopy and determination of the presence and type of antinuclear antibody are of greatest diagnostic value in patients in this disease phase. Secondly, an indurative phase, characterised by tightness of the skin, usually follows the oedematous phase. Here,

Table 3 Survival in systemic sclerosis (\%). Reproduced, with permission, from ref 4

\begin{tabular}{llll}
\hline $\begin{array}{l}\text { Systemic sclerosis } \\
\text { subtype }\end{array}$ & 1 year & 6 years & 12 years \\
\hline Limited cutaneous & 98 & 80 & 50 \\
Diffuse cutaneous & 80 & 30 & 15 \\
\hline
\end{tabular}


sclerodactyly and the classic expressionless face make the diagnosis unmistakable. Ultimately, an atrophic phase occurs, when the skin may actually soften.

Pitting scars over the fingertips, often accompanied by loss of substance of the finger pad, are characteristic findings in both limited and diffuse cutaneous systemic sclerosis. The presence of digital pitting scars is one of the minor criteria for systemic sclerosis. ${ }^{16} \mathrm{Tel}$ angiectasias are commonly found on the hands and face, especially in the limited cutaneous form of systemic sclerosis. Calcinosis occurs commonly on the volar aspect of the fingertips and over joints such as the metacarpophalangeal and interphalangeal joints, where it may ulcerate.

\section{GASTROINTESTINAL TRACT DISEASE}

Gastrointestinal disease is the most commonly recognised visceral manifestation of systemic sclerosis. Dysphagia and heartburn, the most common symptoms, are due to oesophageal dysmotility and oesophageal reflux. Nearly $85 \%$ of patients with systemic sclerosis have been found to have oesophageal reflux using 24 hour pH monitoring of the distal oesophagus. ${ }^{17}$ The oesophagus is not affected in localised scleroderma.

Peristaltic abnormalities may delay gastric emptying and may also affect motility of the small and large intestines, at times giving rise to pseudo-obstruction or malabsorption secondary to bacterial overgrowth. Malabsorption may rarely result from pancreatic insufficiency. A recent study concluded that pancreatic exocrine function is often reduced in patients with systemic sclerosis, but rarely to an extent that is clinically important. ${ }^{18}$ Primary biliary cirrhosis may occur, usually in association with longstanding limited cutaneous systemic sclerosis.

Palliative treatment of gastrointestinal disease is based upon the prevention of gastric reflux and stricture formation by using combinations of antacids, $\mathrm{H}_{2}$ blockers, sucralfate, with elevation of the head of the bed. Severe reflux oesophagitis may respond to treatment with omeprazole. Malabsorption and pseudoobstruction are treated with antibiotics, bowel rest and, at times, parenteral hyperalimentation.

\section{PULMONARY DISEASE}

The prevalence of lung disease ranks second to that of the gastrointestinal tract. Dyspnoea and hypoxia may result from interstitial inflammation and fibrosis, or may be the result of pulmonary hypertension occurring in the absence of parenchymal lung disease. Severe pulmonary hypertension is seen most often in patients with limited cutaneous systemic sclerosis. With recent advances in the treatment of scleroderma renal disease, scleroderma lung disease has become the most common cause of death.

Dyspnoea on exertion is the most common pulmonary complaint and is often accompanied by a non-productive cough. Chest radiographs often show diffuse linear and nodular fibrosis in the lower two thirds of the lung fields, but are relatively insensitive tests of lung disease. Recent studies using thin section computed tomography have shown abnormalities before the onset of dyspnoea or the detection of abnormalities on routine chest radiograph. ${ }^{19}$ Tests of pulmonary function often disclose restrictive lung disease with reduced lung volumes and decreased diffusing capacity. As lung disease progresses, hypoxia and cor pulmonale may occur.

Recently, a number of studies have demonstrated an inflammatory component to the lung disease in a significant percentage of patients with systemic sclerosis. Gallium-67 lung scans often show increased uptake, ${ }^{20}$ but gallium scans are non-specific and not recommended. Studies using bronchoalveolar lavage have shown that a significant proportion of patients with systemic sclerosis have evidence of an 'alveolitis', often before the onset of dyspnoea or abnormal pulmonary function tests or chest radiograph, ${ }^{19} 21$ and most studies concur that the alveolitis is characterised by an increased number of total cells (mostly alveolar macrophages) and an increased percentage and absolute number of neutrophils and eosinophils-similar increases to those described in cryptogenic fibrosing alveolitis. ${ }^{22-26} \mathrm{~A}$ few patients may have a lymphocytic alveolitis, particularly patients with Sjögren's syndrome.

In our study of 43 patients with systemic sclerosis (all non-smokers) an increased bronchoalveolar lavage cell count or an increased percentage of neutrophils, or both, was associated with poorer pulmonary function. ${ }^{27}$ The course of interstitial lung disease in patients with systemic sclerosis has been shown not to be predicted by traditional tests, such as initial
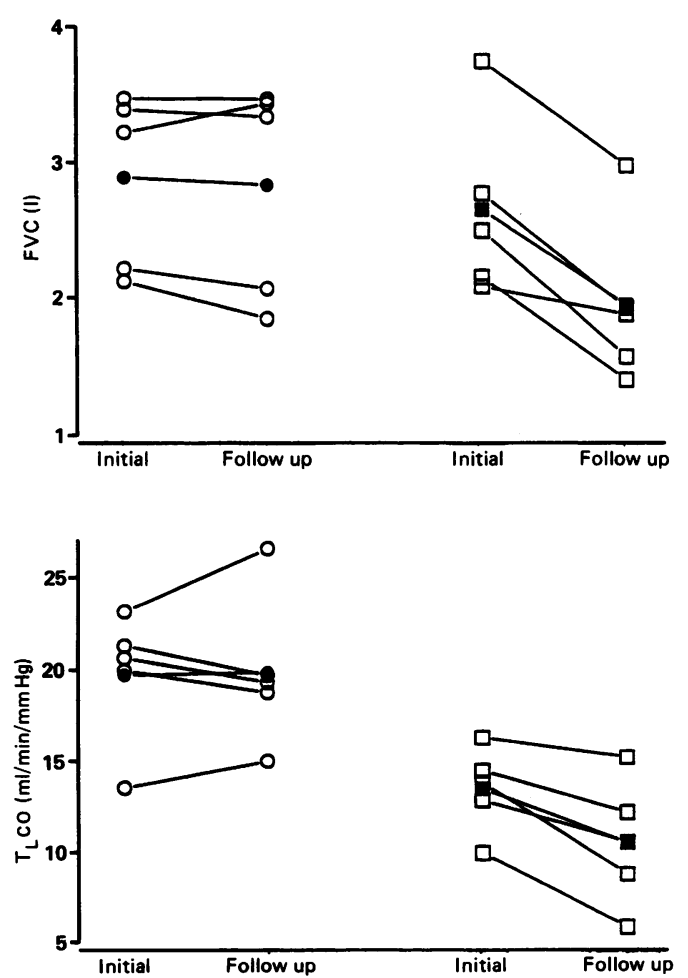

Changes in forced vital capacity (FVC) and carbon monoxide transfer factor $\left(T_{L} \mathrm{CO}\right)$ in 10 patients with systemic sclerosis classified according to bronchoalveolar lavage findings as those without $(\mathrm{O})$ and those with $(\square)$ alveolitis. Solid symbols represent means. ${ }^{27}$ 
chest radiograph or pulmonary function tests, nor by demographic data. In a prospective study of scleroderma lung disease we found that normal bronchoalveolar lavage findings were associated with a stable course, but abnormal findings were associated with worsening dyspnoea, worsening chest radiograph, and significantly greater decline in forced vital capacity and carbon monoxide transfer factor (see figure). ${ }^{27}$ Thus bronchoalveolar lavage may prove to be a useful predictor of the course of scleroderma lung disease.

Treatment of the interstitial lung disease of systemic sclerosis has been disappointing. Our preliminary studies suggest that patients with systemic sclerosis with alveolitis may benefit from treatment with cyclophosphamide, but controlled prospective trials are needed. ${ }^{27}$ Perhaps bronchoalveolar lavage and high resolution computed tomography will prove useful in selecting patients with potentially reversible disease, as well as helpful in monitoring responses to drug treatment.

Bronchoalveolar lavage does provide information about cells and proteins obtained from the lung, a common site of active disease. Products of alveolar macrophages such as fibronectin, a glycoprotein that may serve as a chemoattractant and growth factor for fibroblasts, may play a part in the pathogenesis of scleroderma lung disease. We have found that scleroderma alveolar macrophages release significantly more fibronectin than controls and that the concentration of fibronectin correlates with the degree of alveolitis and correlates negatively with the carbon monoxide transfer factor. ${ }^{28}$ Other growth factors secreted by alveolar macrophages are currently under investigation.

Pulmonary hypertension (in the absence of significant interstitial fibrosis) occurs in about $5 \%$ of patients with limited cutaneous systemic sclerosis but rarely in patients with the diffuse cutaneous subtype. A recent case-control necropsy study showed that intimal thickening and luminal narrowing occur in both subsets of systemic sclerosis, but that such pulmonary vascular changes are most pronounced in patients with limited cutaneous systemic sclerosis. ${ }^{29}$ By the time that patients present with dyspnoea and hypoxia significant pulmonary vascular resistance might have occurred owing to structural luminal narrowing. Thus vasodilator treatment is often unsuccessful at this point. Perhaps the early use of vasodilator or other drug treatment in patients identified as being at risk for pulmonary hypertension (limited cutaneous systemic sclerosis, dilated nailfold capillaries with minimal capillary loss, anticentromere antibody) will forestall the development of this often fatal complication of systemic sclerosis.

RENAL DISEASE

Proteinuria, azotaemia, or hypertension occurs in $45 \%$ of patients with systemic sclerosis. ${ }^{30}$ Of all the visceral organs potentially affected by systemic sclerosis, renal disease has been associated with the highest mortality. Until the introduction of dialysis and potent antihypertensive drugs, renovascular hypertension was uniformly fatal. The characteristic histopathological finding is that of concentric, subendothelial intimal proliferation of small arcuate and interlobular arteries. A functional correlate of this structural abnormality is the reduction in renal cortical blood flow, which may be further compromised by vasospasm associated with Raynaud's phenomenon. ${ }^{30}$

Significant risk factors for the onset of scleroderma renal crisis include anaemia, pericardial effusion, congestive heart failure, and rapid progression of skin thickening. ${ }^{31}$ The renin-angiotensin system plays a major part in the pathogenesis of malignant hypertension secondary to systemic sclerosis. Many such patients have increased plasma renin activity, which may precede or coincide with rapid deterioration in renal function, and many will respond to angiotensin converting enzyme inhibitor treatment with normalisation of blood pressure and, sometimes, reversal of renal failure. The use of captopril and other converting enzyme inhibitors has been associated with a marked reduction in mortality from scleroderma renal crisis, ${ }^{32}$ but not all cases will respond despite normalisation of blood pressure. ${ }^{33} 34 \mathrm{~A}$ recent report described a small percentage (11\%) of patients with systemic sclerosis with renal crisis not accompanied by hypertension. ${ }^{35}$ When compared with patients with systemic sclerosis with hypertensive renal crisis, such cases were more likely to have had microangiopathic haemolytic anaemia and thrombocytopenia, and were more likely to have received high doses of corticosteroids during the two months immediately preceding the renal crisis.

Renal disease in patients who develop renal failure despite treatment has been managed with haemodialysis and transplantation, but experience is limited and success has been variable. Haemodialysis often presents technical problems with vascular access. Contrary to some earlier reports, we and others have found continuous ambulatory peritoneal dialysis to be effective and well tolerated in patients with systemic sclerosis with end stage renal disease. ${ }^{36}$

\section{CARDIAC DISEASE}

The landmark paper by Weiss et al established the entity of scleroderma heart disease 48 years ago. ${ }^{37}$ Heart disease may present as heart failure, arrhythmias, conduction disturbances, or chest pain, all of which may be the result of vascular disease and fibrosis. Weiss et al noted an unusual type of myocardial scarring in the presence of normal extramural coronary arteries. Such scarring is probably antedated by contraction-band necrosis, the classic finding in scleroderma heart disease, which has been produced experimentally by transient interruption of blood flow. Once again, the functional correlate of this structural abnormality may be reversible vasospasm affecting small coronary arteries. Evidence exists for left ventricular dysfunction induced by cold, ${ }^{38}$ as well as cold induced regional perfusion defects. ${ }^{39}$ Structural lesions of the coronary microcirculation may also be 
major determinants of cardiac disease in systemic sclerosis. Some patients with primary scleroderma heart disease have reduced coronary blood flow and coronary reserve after maximal coronary vasodilatation with intravenous dipyridamole. ${ }^{40}$

Coronary vasospasm seems to be reversible with calcium channel blockers such as nifedipine. ${ }^{41}$ As in the case of pulmonary hypertension, some patients may not respond to vasodilator treatment owing to the presence of fixed structural lesions affecting the coronary microcirculation. Studies are needed to identify patients at risk of developing such lesions in the coronary microcirculation so that treatment may be started before irreversible intimal hypertrophy.

\section{Pathogenesis}

GENETIC ASPECTS

A number of cases of familial scleroderma have been reported. ${ }^{42}$ Although no common genetic markers have been identified, asymptomatic relatives have a higher incidence of antinuclear antibodies than controls. ${ }^{43}$ Several population studies have shown an increase in the prevalence of certain HLA types, including DR1, DR3, and DR5, among patients with systemic sclerosis. ${ }^{44}$ A recent study showed that the increased chromosomal breakage rate reported in patients with systemic sclerosis and their first degree relatives is linked to one particular HLA haplotype, HLA Al, B8, DR3. ${ }^{45}$ Of interest is the association of the same haplotype with the severe form of scleroderma-like disease induced by vinyl chloride. ${ }^{46}$

CONNECTIVE TISSUE ASPECTS

The characteristic feature of systemic sclerosis is excessive deposition of collagen and other connective tissue matrix proteins. LeRoy noted that scleroderma dermal fibroblasts synthesise excessive collagen in vitro and that this increased ability to synthesise collagen persists in vitro for a number of passages, before declining towards normal. 47 Increased synthesis of glycosaminoglycans and fibronectin has also been shown. Increased concentrations of mRNA of each of these matrix proteins exist in scleroderma dermal fibroblasts. This may result from increased rates of transcription, but increased half lives of the mRNAs may also contribute to increased matrix synthesis in systemic sclerosis. $^{48} 49$

Recent studies have shown that transforming growth factor $\beta$ may enhance transcription of collagen mRNA through the activation of a promoter region of the collagen gene. ${ }^{50}$ When injected into experimental animals, transforming growth factor $\beta$ causes a mononuclear cell inflammatory response and fibrosis. ${ }^{51}$ Also of potential relevance to systemic sclerosis, transforming growth factor $\beta$ induces the autocrine production of a potent fibroblast mitogen, platelet derived growth factor, ${ }^{52}$ and it inhibits endothelial cell proliferation in vitro. ${ }^{53}$ These and other studies support a hypothetical role for transforming growth factor $\beta$ in the induction of the vascular and interstitial lesions of systemic sclerosis. $^{54}$

\section{VASCULAR ASPECTS}

The physiological (Raynaud's phenomenon) and pathological (in vivo and postmortem) features of vascular disease in systemic sclerosis have been discussed. Raised plasma concentrations of factor VIII/von Willebrand factor and a platelet product, $\beta$ thromboglobulin, further attest to microvascular and endothelial injury. ${ }^{55}$ The mediator of endothelial injury in systemic sclerosis remains controversial. Two recently defined molecules which are capable of causing endothelial injury are tumour necrosis factor $\alpha^{56}$ and transforming growth factor $\beta .^{53}$ Each has the ability to stimulate fibroblast proliferation, as well as induce endothelial injury.

\section{IMMUNOLOGICAL ASPECTS}

The common occurrence of antinuclear antibodies and the presence of mononuclear cell infiltrates in the dermis suggest a role for altered immune responsiveness in the pathogenesis of systemic sclerosis. Additional indirect support for this notion is the occurrence of sclerodermalike lesions in patients with chronic graft versus host disease. These and other immunological features have been reviewed recently. ${ }^{1}$ New data implicating the immune response in the pathogenesis of systemic sclerosis are reviewed below.

As noted above, antinuclear antibodies are often found in patients with systemic sclerosis and their first degree relatives, up to $95 \%$ of the former and $57 \%$ of the latter, when a rapidly dividing, human cell substrate such as HEp-2 is used. ${ }^{43}$ Two particular antinuclear antibodies deserve mention because of their subset specificity and potential role in pathogenesis. The first is the anticentromere antibody, which recognises three human chromosomal antigens, and which is associated with limited cutaneous systemic sclerosis and patients with Raynaud's phenomenon at risk of developing limited disease. ${ }^{57}$ The association of anticentromere antibody with certain nailfold capillary abnormalities has been noted ${ }^{12}$; both are useful in screening patients with Raynaud's phenomenon for underlying systemic sclerosis. ${ }^{1314}$ The second, anti-Scl-70, found in about $30 \%$ of patients with diffuse cutaneous systemic sclerosis, is an autoantibody directed against the nuclear enzyme, DNA topoisomerase I. ${ }^{58}$ Another autoantibody, found in a smaller percentage of patients with diffuse cutaneous systemic sclerosis, seems to be directed against a nucleolar enzyme, RNA polymerase I. ${ }^{59}$ Recently it has been suggested that topoisomerase I may accelerate collagen gene transcription by virtue of its ability to bind to promoter regions and other sites on collagen genes, leading Douvas to propose that inhibitors of topoisomerase I may ultimately prove useful in controlling the excessive collagen synthesis which characterises systemic sclerosis. ${ }^{60}$

Activation of the complement pathways has been shown recently in patients with systemic sclerosis. ${ }^{61}$ Newly developed techniques 
showed that concentrations of activated complement components were high in many patients with systemic sclerosis and these concentrations reflected the clinical severity.

The presence of mononuclear cells in the dermis of patients with systemic sclerosis has generated interest in the products of such cells and their potential effects on fibroblasts. Mast cells are present in the dermis of patients with systemic sclerosis, ${ }^{62}$ and in a number of experimental models and pathological states of fibrosis, including graft versus host disease. Inhibitors of mast cell degranulation reduce the fibrosis which occurs spontaneously in one experimental model of scleroderma, the tight skin mouse. ${ }^{63} 64$ It remains to be determined whether such inhibitors can modify the course of systemic sclerosis.

Soluble products of lymphocytes and monocytes have recently been studied for their effects on vascular endothelium and fibroblasts. One such cytokine, interferon $\gamma$, can down regulate collagen synthesis by fibroblasts in vitro. Interferon $\gamma$ exerts its action at the level of transcription by decreasing mRNA for procollagen, and has a longlasting effect. ${ }^{65} 66$ In one study a 72 hour exposure to interferon $\gamma$ reduced procollagen mRNA concentrations in scleroderma fibroblast cell lines to those shown by control fibroblasts. ${ }^{66}$ Clinical trials of recombinant interferon $\gamma$ in systemic sclerosis are currently under way.

Other cytokines are also potentially relevant to the pathogenesis of systemic sclerosis. Interleukin 1 is mitogenic to fibroblasts, as is an inhibitor to interleukin 1 produced by mononuclear cells from patients with systemic sclerosis. ${ }^{67}$ Lymphotoxin and tumour necrosis factor $\alpha$, present in scleroderma serum samples, may also be important mediators. ${ }^{68}$ Tumour necrosis factor $\alpha$ has been shown in vitro to injure endothelial cells and to stimulate fibroblast proliferation. ${ }^{5668}$ Future treatments may use modifiers of the biological response(s) to such cytokines.

\section{Special considerations}

Localised scleroderma is similar to systemic sclerosis histopathologically, but effects of the former condition are limited to the skin, subcutaneous tissue, fascia, and adjacent muscle. Depending upon the location and extent of affected skin, localised scleroderma may be classified as linear or morphoea (plaque or generalised). In linear scleroderma sclerotic skin occurs in a band-like distribution, often crossing joint lines and resulting in contractures. Facial hemiatrophy may be regarded as a form of linear scleroderma affecting the face and scalp (en coup de sabre). Morphoea may occur as circumscribed plaques of sclerotic skin or as a more generalised, symmetric process.

Raynaud's phenomenon is rare among patients with localised scleroderma, unlike those with systemic sclerosis. Antinuclear antibodies may be positive in about $50 \%$ of patients with localised scleroderma, using the sensitive HEp2 substrate. ${ }^{69}$ The nature of the nuclear antigen(s) with which serum samples from patients with localised scleroderma react is unknown, but it differs from topoisomerase I and centromere antigens. ${ }^{70}$ Eosinophilia is more common than in systemic sclerosis $(31 \% v 7 \%)$, but less common than in eosinophilic fasciitis. ${ }^{71}$ The degree of blood eosinophilia may reflect disease activity.

The cause of localised scleroderma is unknown. Much excitement was generated by reports suggesting a spirochaetal cause (Borrelia burgdorferi), ${ }^{72}$ but most subsequent investigations from other geographical locations have failed to confirm this association..$^{73} 74$

Diffuse fasciitis with eosinophilia (eosinophilic fasciitis or Shulman's disease) is a syndrome characterised by scleroderma-like skin changes, fasciitis, and blood eosinophilia. It falls within the spectrum of scleroderma, and histologically is similar in many respects to what has been described as 'morphoea profunda'. ${ }^{75}$ The characteristic histopathological features are thickening and hyalinisation of collagen bundles in the deep dermis and of the septa in the subcutis; an inflammatory cell infiltrate composed mainly of lymphocytes and sometimes eosinophils; and slight deposits of mucin. Such changes differ from conventional morphoea because of deeper involvement and more pronounced inflammatory cell infiltration.

Recently, an epidemic known as the eosinophilia-myalgia syndrome was reported, initially and predominantly from the United States, associated with the ingestion of the essential amino acid L-tryptophan. ${ }^{76}$ This syndrome is similar in some respects to sporadic cases of eosinophilic fasciitis; in fact, retrospective studies have shown that a significant proportion of cases of eosinophilic fasciitis were associated with the ingestion of L-tryptophan. The eosinophilia-myalgia syndrome also resembles in many respects the toxic oil syndrome, which occurred as an epidemic in Spain in $1981 .^{77}$ Thus far the eosinophilia-myalgia syndrome has affected over 1500 subjects and has been linked to more than 20 deaths.

Many patients with eosinophilia-myalgia syndrome have scleroderma-like changes affecting the skin and subcutaneous tissue, including the fascia and adjacent muscles, ${ }^{7}$ similar to those described above in morphoea profunda or eosinophilic fasciitis. Unusual features of this syndrome include an eosinophilic pneumonitis, hepatitis, and neuropathy in some patients. The last of these may be severe and debilitating, resulting in respiratory failure, and has been responsible for most of the deaths attributed to the syndrome. A number of cases have also been described with clinical and histopathological evidence of pulmonary hypertension. ${ }^{78}$ Pneumonitis, pulmonary hypertension, and neuropathy were also prominent features of the toxic oil syndrome.

Several cases of a similar illness were reported in patients receiving $\mathrm{L}-5$-hydroxytryptophan for treatment of neurological disorders, ${ }^{79}$ raising the question of the role of tryptophan metabolism in these and other fibrosing conditions, including systemic sclerosis. Biochemical studies of tryptophan metabolites have shown abnormalities in these patients, ${ }^{79}$ as well as in 
patients in the active phase of eosinophilic fasciitis. ${ }^{80}$ These studies have shown increased concentrations of tryptophan metabolites, kynurenine and quinolinic acid, in the plasma and urine. The pattern of increased kynurenine and quinolinic acid concentrations in patients in the active phase of their illness is consistent with increased activity of the rate limiting enzyme in the kynurenine pathway, indoleamine-2,3dioxygenase. Inflammatory mediators, such as endotoxin and interferon $\gamma$, are known to stimulate the activity of indoleamine-2,3dioxygenase. It remains to be determined whether endotoxin or interferon $\gamma$, or both, play a part in the biochemical abnormalities and pathogenesis of the current eosinophilia-myalgia syndrome epidemic. Further studies of tryptophan metabolism in patients with eosinophiliamyalgia syndrome or eosinophilic fasciitis may provide information which is applicable to the pathogenesis of systemic sclerosis.

The eosinophilia and oedematous skin changes, as well as the pneumonitis, associated with eosinophilia-myalgia syndrome generally respond well to corticosteroid treatment. Neuropathy and pulmonary hypertension may persist, and chronic skin changes are now being seen. The natural history of this new epidemic remains to be determined.

\section{Childhood scleroderma}

Scleroderma is rare in childhood, and the clinical presentation is even more varied than in adult life. ${ }^{81}$ Juvenile onset scleroderma may take the form of localised scleroderma (linear or morphoea), including eosinophilic fasciitis, ${ }^{82}$ or it may occur as systemic sclerosis. In the latter case Raynaud's phenomenon is commonly the presenting symptom. Skin involvement may be classified as localised or diffuse, as with adult onset scleroderma. Visceral organ involvement is similar to the adult form, with oesophageal dysmotility being common, and with cardiac and pulmonary disease primarily responsible for morbidity and mortality. With an HEp- 2 cell substrate the prevalence of antinuclear antibodies has been shown to be similar to that in adult scleroderma: in $100 \%$ of children with systemic sclerosis and in $67 \%$ of children with localised scleroderma. ${ }^{81}$ Anticentromere antibody has been demonstrated in the rare case of juvenile onset CREST syndrome. ${ }^{83}$

1 Silver R M, LeRoy E C. Systemic sclerosis (scleroderma). In Samter $M$, Talmage $D$ W, Frank $M M$, Austen $K \mathbf{F}$, Claman $\mathrm{H}$ N, eds. Immunological diseases. 4th ed. Boston: Little, Brown, 1988: 1459-500.

2 Jayson M I V, Black C M. Systemic sclerosis: scleroderma. New York: Wiley, 1988.

3 Rocco V L, Hurd E R. Scleroderma and scleroderma-like disorders. Semin Arthritis Rheum 1986; 16: 22-69.

4 LeRoy E C, Black C, Fleischmajer R, et al. Scleroderma (systemic sclerosis): classification, subsets and pathogenesis. (systemic sclerosis): classification,

5 Masi A T. Classification of systemic sclerosis (scleroderma): relationship of cutaneous subgroups in early disease to outcome and serologic reactivity. I Rhermatol 1988; 15 : 894-8.

6 Maricq H R, Weinrich M C. Diagnosis of Raynaud's phenomenon assisted by color charts. $\mathcal{f}$ Rheumatol 1988 15: 454-9.

7 Silver R M, Heyes M P, Maize J C, Quearry B, VionnetFuasset M, Sternberg E M. Scleroderma, fasciitis, and eosinophilia associated with the ingestion of tryptophan $N$ Engl f Med 1990; 322: 874-81.

8 Priollet P, Vayssairat M, Housset E. How to classify
Raynaud's phenomenon. Long-term follow-up study of 73 cases. Am f Med 1987; 83: 494-9.

9 Maricq H R, Weinrich M C, Keil J E, LeRoy E C. Prevalence of Raynaud's phenomenon in the general population. A preliminary study by questionnaire. $\mathcal{F}$ Chronic Dis 1986; 39: 423-7.

10 Harper F E, Maricq H R, Turner R E, Lidman R W, LeRoy E C. A prospective study of Raynaud's phenomenon and early connective tissue disease. A five-year report. $A m \boldsymbol{F}$ early connective tissue

11 Fitzgerald O, Hess E V, O'Connor G T, Spencer-Green G. Prospective study of the evolution of Raynaud's phenomenon. Am J Med 1988; 84: 718-26.

12 Chen Z, Silver R, Ainsworth S K, Dobson R L, Rust P, Maricq H R. Association between fluorescent antinuclear antibodies, capillary patterns and clinical features in scleroderma spectrum disorders. Am f Med 1984; 77: 812-22.

13 Kallenberg C G M, Wouda A A, Hoet M H, van Venrooij W J. Development of connective tissue disease in patients presenting with Raynaud's phenomenon: a six year follow up with emphasis on the predictive value of antinuclear antibodies as detected by immunoblotting. Ann Rheum Dis 1988; 47: 634-41.

14 Wollersheim $H$, Thien Th, Hoet $M H$, van Venrooij W J. The diagnostic value of several immunological tests for The diagnostic value of several immunological tests for antinuclear antibody in predicting the development of connective tissue disease in patients presenting with Raynaud's
535-41.

15 Lomeo R M, Cornella R J, Schabel S I, Silver R M. Progressive systemic sclerosis sine scleroderma presenting as pulmonary interstitial fibrosis. Am $\mathcal{F}$ Med 1989; 87: 525-7.

16 Masi A T, Rodnan G P, Medsger T A Jr, et al. Preliminary criteria for the classification of systemic sclerosis (scleroderma). Arthritis Rheum 1980; 23: 581-90.

17 Zaninotto G, Peserico A, Costanini M, et al. Oesophageal motility and lower oesophageal sphincter competence in progressive systemic sclerosis and localized scleroderma. Scand J Gastroenterol 1989; 24: 95-102.

18 Hendel L, Worning H. Exocrine pancreatic function in patients with progressive systemic sclerosis. Scand $\mathcal{f}$ Gastroenterol 1989; 24: 461-6.

19 Harrison N K, Glanville A R, Strickland B, et al. Pulmonary involvement in systemic sclerosis: the detection of early changes by thin section CT scan bronchoalveolar and 99m Tc-DTPA clearance. Respir Med 1989; 83: 403-14.

20 Furst D E, Davis J A, Clements P J, Chopra S K, Theofilopoulos A N, Chia D. Abnormalities of pulmonary vascular dynamics and inflammation in early progressive vascular dynamics and inflammation in early progress
systemic sclerosis. Arthritis Rheum 1981; 24: 1403-8.

21 Wallaaert B, Hatron P Y, Grosbois J M, Tonnel A B, Devulder B, Voison C. Subclinical pulmonary involvement
Dent in collagen-vascular diseases assessed by bronchoalveolar lavage. Relationship between alveolitis and subsequent change in lung function. Am Rev Respir Dis 1986; 133: 574-80.

22 Konig G, Lunderschmidt C, Hammer C, Adelmann-Grill B C, Braun-Falco O, Fruhmann G. Lung involvement in scleroderma. Chest 1984; 85: 318-24.

23 Silver R M, Metcalf J M, Stanley J H, LeRoy E C. Interstitial lung disease in scleroderma. Analysis by bronchoalveolar lung disease in scleroderma. Analysis by brot

24 Silver R M, Metacalf J M, LeRoy E C. Interstitial lung disease in scleroderma: immune complex in sera and bronchoalveolar lavage fluid. Arthritis Rheum 1986; 29: 525-31.

25 Owens G R, Paradis I L, Gryzan S, et al. Role of inflammation in the lung disease of systemic sclerosis: comparison with idiopathic pulmonary fibrosis. $7 \mathrm{Lab} \mathrm{Clin}$ Med 1986; 107: 253-60.

26 Rossi G A, Bitterman P B, Rennard S I, Ferrans V J, Crystal R G. Evidence for chronic inflammation as a component of the interstitial lung disease associated with progressive systemic sclerosis. Am Rev Respir Dis 1985; 131: 612-7.

27 Silver R M, Miller K S, Smith E A, Kinsella M B, Schabel S I. Evaluation and management of scleroderma lung disease I. Evaluation and management of scleroderma lung disease using bronchoalveolar lavage. Am J Med 1990; 88: 470-6.
Kinsella M B, Smith E A, Miller K S, LeRoy E C, Silver R $M$. Spontaneous production of fibronectin by scleroderma alveolar macrophages. Arthritis Rheum 1989; 32: 577-83.

29 Al-Sabbagh M R, Steen V D, Zee B C, et al. Pulmonary arterial histology and morphometry in systemic sclerosis: a case-control autopsy study. $\mathcal{F}$ R heumatol 1989; 16: 1038-42.

30 Cannon P J, Hassar M, Case D B, Casarella W J, Sommers S $C$, LeRoy E C. The relationship of hypertension and renal failure in scleroderma (progressive systemic sclerosis) to structural and functional abnormalities of the renal cortical circulation. Medicine (Baltimore) 1974; 53: 1-46.

31 Steen V D, Medsger T A Jr, Osial T A, Jr, Ziegler G L, of renal involvement in progressive systemic sclerosis. $\boldsymbol{A m} \mathcal{F}$ of renal involvement in

32 Steen V D, Medsger T A Jr. Outcome of scleroderma renal crisis in the pre- and post-captopril eras (abstract). Arthritis Rheum 1988; 31: S21.

33 Waeber B, Schaller M-D, Wauters J-P, Brunner H R. Deterioration of renal function in hypertensive patients with scleroderma despite blood pressure norma

34 Spooner M S, LeRoy E C. The changing face of severe scleroderma in five patients. Clin Exp Rheumatol 1990; 8: 101-5. 
35 Helfrich D J, Banner B, Steen V D, Medsger T A Jr. Normotensive renal failure in systemic sclerosis. Arthritis Rheum 1989; 32: 1128-34.

36 Jones B, Trevillian P, Lake N. Continuous ambulatory peritoneal dialysis in scleroderma. Nephron 1990; 54: 107-8.

37 Weiss S, Stead E A Jr, Warren J V, Bailey O T. Scleroderma heart disease. With a consideration of certain other visceral heart disease. With a consideration of certain other
manifestations. Arch Intern Med 1943; 71: 749-76.

38 Ellis $W W$, Baer A N, Robertson $R$ M, Pincus $T$ Kronenberg $M$ W. Left ventricular dysfunction induced by cold exposure in patients with systemic sclerosis. $A m \mathcal{J} M e d$ cold exposure in pa
1986; 80: $385-92$.

39 Alexander E L, Firestein G S, Weiss J L, et al. Reversible cold-induced abnormalities in myocardial perfusion and function in systemic sclerosis. Ann Intern Med 1986; 105 661-8.

40 Nitenberg A, Foult J M, Kahan A, et al. Reduced coronary flow and resistance reserve in primary scleroderm myocardial disease. Am Heart 7 1986; 112: 309-15.

41 Kahan A, Devaux J Y, Amor B, et al. Nifedipine and thallium-201 myocardial perfusion in progressive systemic sclerosis. N Engl f Med 1986; 314: 1397-402.

42 McGregor A R, Watson A, Yunis E, et al. Familial clustering of scleroderma spectrum disease. Am $\mathcal{F}$ Med 1988; 84: of scleroder.

43 Takehara K, Moroi Y, Ishibashi Y. Antinuclear antibodies in the relatives of patients with systemic sclerosis. $\mathrm{Br} \mathcal{J}$ Dermatol 1985; 112: 23-33.

44 Black C M, Welsh K I, Maddison P J, Jayson M I V, Bernstein R M. HLA antigens, autoantibodies and clinica subsets in scleroderma. Br $\mathcal{F}$ Rheumatol 1984; 23 : 267-71.

45 Rittner G, Schwanitz G, Baur M P, et al. Family studies in scleroderma (systemic sclerosis) demonstrating an HLAlinked increased chromosomal breakage rate in cultured lymphocytes. Hum Genet 1988; 81: 64-70.

46 Black C M, Welsh K I, Walker A E, et al. Genetic susceptibility to scleroderma-like syndrome induced by susceptibility to scleroderma-like synd
vinyl chloride. Lancet 1983 ; i: $53-5$.

47 LeRoy E C. Connective tissue synthesis by scleroderma skin fibroblasts in cell culture. $\mathcal{F} \operatorname{Exp} M$ Med 1972; 135: 1351-62.

48 Kahari V-M, Multimaki P, Vuorio E. Elevated pro-alpha-2 (I) collagen mRNA levels in cultured scleroderma fibroblasts results from an increased transcription rate of the corresponding gene. FEBS Letters 1987; 215: 331-4.

49 Kahari V-M, Vuorio E I. Increased half-lives of procollagen mRNAs may contribute to the elevated procollagen mRNA levels in cultured scleroderma fibroblasts. Medical Science Research 1987; 15: 417-8.

50 Rossi P, Karsenty G, Roberts A B, Roche N S, deCrombrugghe $B$. A nuclear factor 1 binding site mediates the transcriptional activation of a type 1 collagen promote by transforming growth factor $\beta$. Cell 1988; 52: 405-14.

51 Roberts A B, Sporn M B, Assoian R K, et al. Transforming growth factor type $\beta$ : rapid induction of fibrosis and in vitro. Proc Natl Acad Sci USA 1986; 83: 4167-71.

52 Leof E B, Proper J A, Goustin A S, Shipley G D, DiCorleto $P$ E, Moses H L. Induction of c-sis mRNA and activity similar to platelet-derived growth factor by transforming similar to platelet-derived growth factor by transforming
growth factor-beta: a proposed model for indirect mitogenesis involving autocrine activity. Proc Natl Acad Sc USA 1986; 83: 2453-7.

53 Takehara K, LeRoy E C, Grotendorst G R. TGF- $\beta$ inhibition of endothelial cell proliferation: alteration of EGF binding and EGF-induced growth-regulatory (competence) gene expression. Cell 1987; 49: 415-22.

54 LeRoy E C, Smith E A, Kahaleh M B, Trojanowska M, Silver R M. A strategy for scleroderma (systemic sclerosis): Is transforming growth factor beta the answer? Arthritis Is transforming growth

55 Kahaleh M B, Osborn I, LeRoy E C. Increased factor VIII/von Willebrand factor antigen and von Willebrand factor activity in scleroderma and in Raynaud's phenomenon. Ann Intern Med 1981; 94: 482-4.

56 Sato N, Goto T, Haranaka K, et al. Actions of tumor necrosis factor on cultured vascular endothelial cells: morphologic modulation, growth inhibition, and cytotoxicity. F Natl Cancer Inst 1986; 76: 1113-21.

57 Earnshaw W, Bordwell B, Marino C, Rothfield N. Three human chromosomal autoantigens are recognized by sera from patients with anti-centromere antibodies. 7 Clin Invest from patients with
1986; 77: 426-30.
58 Shero J H, Bordwell B, Rothfield N G, Earnshaw W C. High titers of autoantibodies to topoisomerase I (Scl-70) in sera from scleroderma patients. Science 1986; 231: 737-40.

59 Reimer G, Rose K M, Scheer L I, Tan E M. Autoantibody to RNA polymerase I in scleroderma sera. $\mathcal{F}$ Clin Invest 1987 ; 79: 65-72.

60 Douvas A. Does Scl-70 modulate collagen production in systemic sclerosis? Lancet 1988, ii: 475-7.

61 Senaldi G, Lupoli S, Vergani D, Black C M. Activation of the complement system in systemic sclerosis. Relationship to
clinical severity. Arthritis Rheum 1989; 32: 1262-7.

62 Hawkins R A, Claman H N, Clark R A F, Steigerwald J C. Increased dermal mast cell populations in progressive systemic sclerosis: A link in chronic fibrosis? Ann Intern Med 1985; 102: 182-6.

63 Walker M A, Harley R A, LeRoy E C. Inhibition of fibrosis in TSK mice by blocking mast cell degranulation. F Rheumatol 1987; 14: 299-301.

64 Walker M, Harley R, LeRoy E C. Ketotifen prevents skin fibrosis in the tight skin mouse. $\mathcal{F}$ Rheumatol 1990; 17: 57-9.

65 Duncan M R, Berman B. Persistence of a reduced collagen producing phenotype in cultured scleroderma fibroblasts after short term exposure to interferons. $\mathcal{f}$ Clin Invest 1987 79: $1318-24$.

66 Kahari V M, Heino J, Vuorio T, Vuorio E. Interferon and interferon gamma reduce excessive synthesis and procollagen mRNA levels of scleroderma fibroblasts in culture. Biochim Biophys Acta 1988; 968: 4550.

67 Sandborg C I, Berman M A, Andrews B S, Mirick G R, Frio $G$ J. Increased production of an interleukin I (IL1) inhibitor with fibroblast stimulating activity by mononuclear cells from patients with scleroderma. Clin Exp Immunol 1986; 66: 312-9.

68 Kahaleh M B, Smith E A, Soma Y, LeRoy E C. Effect of lymphotoxin and tumor necrosis factor on endothelial and connective tissue cell growth and function. Clin Immunol Immunopathol 1988; 49: 261-72.

69 Falanga V, Medsger T A Jr, Reichlin M, Rodnan G P. Linear scleroderma. Clinical spectrum, prognosis, and laboratory
abnormalities. Ann Intern Med 1986; 104: 849-57.

70 Kikuchi K, Takehara K, Ishibashi Y. Antinuclear antibodies in localized scleroderma: unique staining in chromosome spreads. J Am Acad Dermatol 1989; 21: 1301-3.

71 Falanga V, Medsger T A Jr. Frequency, levels, and significance of blood eosinophilia in systemic sclerosis, localized scleroderma, and eosinophilic fasciitis. $\mathcal{F}$ Am Acad Dermato 1987; 17: 648-56.

72 Aberer E, Stanek G, Ertl M, Neumann R. Evidence for spirochetal origin of circumscribed scleroderma (morphea). Acta Derm Venereol (Stockh) 1987; 67: 225-31.

73 Lecerf V, Bagot M, Revuz J, Touraine R, Dournon E. Borrelia burgdorferi and localized scleroderma. Arch Borrelia burgdorferi and

74 Garioch J J, Rashid A, Thomson J, Seywright M. The relevance of elevated Borrelia burgdorferi titres in localized scleroderma. Clin Exp Dermatol 1989; 14: 439-41.

75 Su W P D, Person J R. Morphea profunda. A new concept and a histopathologic study of 23 cases. Am $\mathcal{F}$ Dermatopathol 1981; 3: 251-60.

76 Anonymous Eosinophilia myalgia syndrome New Mexico. MMWR 1989; 38: 765-7.

77 Toxic epidemic syndrome study group. Toxic epidemic syndrome, Spain, 1981. Lancet 1982; ii: 697-702.

78 Tazelaar H D, Myers J L, Drage C W, King Jr T E, Aguayo $S$, Colby $T$ V. Pulmonary disease associated with L tryptophan-induced eosinophilic myalgia syndrome. tryptophan-induced eosinophilic myalgia syndrome.
Clinical and pathologic features. Chest 1990; 97: 1032-6.

79 Sternberg E M, Van Woert M H, Young S N, et al. Development of a scleroderma-like illness during therapy with L-5-hydroxytryptophan and carbidopa. $N$ Englf $\mathrm{Med}$ 1980; 303: 782-7.

80 Stachow A, Jablonska S, Kencka D. Tryptophan metabolism in scleroderma and eosinophilic fasciitis. In: Black $C M$, Myers A R, eds. Systemic sclerosis (scleroderma). New York: Gower Medical, 1985: 130-4.

81 Bernstein R M, Pereira R S, Holden A J, Black C M, Howard A, Ansell B M. Autoantibodies in childhood scleroderma. Ann Rheum Dis 1985; 44: 503-6.

82 Grisanti M W, Moore T L, Osborn T G, Haber P L Eosinophilic fasciitis in children. Semin Arthritis Rheum 1989; 19: 151-7.

83 Burge S M, Ryan T J, Dawber R P R. Juvenile onset systemic sclerosis. f R Soc Med 1984; 77: 793-4. 